\title{
Multivariate Optimization Applied to the Synthesis of Meglumine Antimoniate with Low Levels of Trivalent Antimony
}

\author{
Henrique J. F. Fabrino, ${ }^{a}$ Frédéric J. G. Frezard, ${ }^{b}$ Ana Carolina B. de Oliveira, ${ }^{b}$ \\ Letícia M. Costa ${ }^{a}$ and Cynthia P. Demicheli ${ }^{\circledR} * a$
}

\author{
${ }^{a}$ Departamento de Química, Instituto de Ciências Exatas (ICEX), Universidade Federal de Minas Gerais, \\ Avenida Antônio Carlos, 6627, Pampulha, 31270-901 Belo Horizonte-MG, Brazil \\ ${ }^{b}$ Departamento de Fisiologia e Biofísica, Universidade Federal de Minas Gerais, \\ Av. Antônio Carlos, 6627, Pampulha, 31270-901 Belo Horizonte-MG, Brazil
}

\begin{abstract}
Meglumine antimoniate (MA) is a pentavalent antimony $\left(\mathrm{Sb}^{\mathrm{v}}\right)$ drug recommended for the treatment of leishmaniasis. It is known that the trivalent antimony $\left(\mathrm{Sb}^{\mathrm{III}}\right)$ present as a residue in MA contributes to the drug side effects. In this article, multivariate optimization was used in the synthesis of MA in order to obtain a drug with low levels of $\mathrm{Sb}^{\mathrm{III}}$. Four variables (source of antimony, temperature, water volume and $\mathrm{pH}$ ) were preliminarily evaluated by $2^{4-1}$ fractional factorial design. Central composite design (CCD) was used to determine the optimal synthesis conditions, using two different sources of $\mathrm{Sb}^{\mathrm{v}}$ and the significant variables selected in a fractional factorial design. Response surface methodology obtained by $\mathrm{CCD}$ provided a model with non-significant regression $(p=0.05)$ for the synthetic route via $\mathrm{KSb}(\mathrm{OH})_{6}$. On the other hand, synthetic route via $\mathrm{SbCl}_{5}$ reached minimum value of $\mathrm{Sb}^{\mathrm{III}}$ content of $0.172 \%$ and significant regression, and it was selected for further evaluations. The analysis of $\mathrm{MA}$ formulations synthesized with $\mathrm{SbCl}_{5}$ under optimized conditions revealed the efficiency of multivariate optimization to reduce $\mathrm{Sb}^{\mathrm{III}}$ content. In addition, the monitoring of some physicochemical parameters of these formulations maintained at $40{ }^{\circ} \mathrm{C}$ for 90 days, showed that stability was not altered at $95 \%$ confidence level.
\end{abstract}

Keywords: leishmaniasis, meglumine antimoniate, multivariate optimization, response surface methodology, formulation stability

\section{Introduction}

Leishmaniasis is a neglected tropical disease caused by protozoa parasites from over 20 Leishmania species (Trypanosomatidae), transmitted by the bite of over 90 infected female sandfly species (Phlebotomine). ${ }^{1}$ There are three main forms of the disease: cutaneous leishmaniasis (CL), the most common form, which causes skin lesions; mucocutaneous leishmaniasis (MCL), leading to partial or total destruction of mucous membranes; and visceral leishmaniasis (VL), a fatal disease if not treated appropriately. It is estimated that 700,000 to 1 million new cases occur annually worldwide. ${ }^{1}$

In the 1940s, two pentavalent antimonials started being used to treat the disease, and they are still the most widely used drugs, particularly antimony sodium stibogluconate, and meglumine antimoniate (MA).-5 These compounds should be administered parenterally daily (typically $20 \mathrm{mg}$

*e-mail: demichel@ufmg.br, cydemich@gmail.com
$\mathrm{Sb}$ per $\mathrm{kg}$ per day for 20-30 days, not exceeding $850 \mathrm{mg}$ of $\mathrm{Sb}) .2,4,5$ Antimonial therapy is frequently accompanied by local pain during parenteral injections and systemic side effects, requiring very close medical supervision. Typical side effects include nausea, vomiting, weakness, myalgia, abdominal cramps, diarrhea, rash, hepatotoxicity and cardiotoxicity. ${ }^{2,4,6}$

It is generally accepted that $\mathrm{Sb}^{\mathrm{III}}$ present as a residue in pentavalent antimonials or produced in tissues through the reduction of $\mathrm{Sb}^{\mathrm{V}}$ into $\mathrm{Sb}^{\mathrm{III}},{ }^{7-11}$ is responsible for their side effects and antileishmanial action., ${ }^{4,12}$ Residual $\mathrm{Sb}^{\mathrm{III}}$ may also be related to the development of antimonial drug resistance. Studies on the mechanism related to $\mathrm{Sb}^{\mathrm{III}}$ action suggested that it compromises thiol homeostasis by depleting intracellular glutathione and inhibiting glutathione reductase. ${ }^{11,13,14}$ Trivalent antimony increases oxidative stress and leads to apoptosis by increasing reactive oxygen species (ROS). ${ }^{11,14-16}$

As an attempt to reduce the side effects of antimonial therapy, important efforts have been devoted to the 
preparation of less toxic compounds, ${ }^{4,17}$ as well as the development of oral and topical formulations. ${ }^{18,19}$

Demicheli et al. ${ }^{17}$ proposed two new synthetic processes to produce MA, using $\mathrm{KSb}(\mathrm{OH})_{6}$ or $\mathrm{SbCl}_{5}$ as antimony sources. The MA obtained from the former was found to be less cytotoxic in vitro than the MA obtained from the latter and by the commercial drug. ${ }^{20}$ Moreover, $\mathrm{KSb}(\mathrm{OH})_{6}$ led to a lower level of apoptosis in the liver after parenteral administration in mice with VL, when compared to commercial drug. ${ }^{12}$ It was then proposed that the lower toxicity of MA prepared from $\mathrm{KSb}(\mathrm{OH})_{6}$ may be due to the lower amount of $\mathrm{Sb}^{\mathrm{III}}$ residue. ${ }^{12,20}$ Comparative tests in a murine model of VL showed that oral synthetic formulations (300 mg Sb per $\mathrm{kg}$ of body weight per $12 \mathrm{~h}$ for 30 days) were as efficacious as commercial drug used parenterally (80 mg Sb per kg of body weight per $24 \mathrm{~h}$ for 30 days)..$^{21}$

The efficiency of MA could be associated to the concentration of $\mathrm{Sb}^{\mathrm{V}}$ and its toxicity related to the presence of $\mathrm{Sb}^{\mathrm{III}}$ as a contaminant. Thus, it is important to determine the concentration of these two species as minimum quality parameters for drugs used in the treatment of leishmaniasis. For this purpose, a method for inorganic $\mathrm{Sb}$ speciation at concentrations in the $\mu g \mathrm{~L}^{-1}$ range using hydride generation associated with atomic absorption spectrometry (HG-AAS) was recently developed by our group. ${ }^{22}$

The traditional univariate approach has been consistently used to optimize the parameters that affect the performance of reactions, requiring a large number of experiments and, consequently, increasing reagent and time consumption. Furthermore, possible interactions between variables are ignored, so that the true ideal conditions may not be achieved. On the other hand, the multivariate optimization technique uses experimental design to efficiently obtain the best desirable characteristics, using a smaller number of experiments, understanding the interactions between variables and providing statistical models.

In this study, the experimental conditions for the synthesis of meglumine antimoniate were developed, using multivariate optimization, with the purpose of obtaining a drug with lower $\mathrm{Sb}^{\mathrm{III}}$ contents for a safer and effective leishmaniasis treatment. Among experimental design methodologies, fractional factorial design ${ }^{23,24}$ allows to understand the effects of a greater number of factors with fewer observations. Central composite design (CCD), ${ }^{25}$ as a response surface methodology (RSM), was useful in modeling and optimizing the effective parameters of the synthesis. This study also focused on the development of candidate formulations for oral and topical administration, establishing minimum quality parameters for drugs used globally in leishmaniasis therapy, evaluating not only the concentration of $\mathrm{Sb}^{\mathrm{III}}$ generated, but also the stability of the product.

\section{Experimental}

Instrumentation

The temperature of the MA synthesis reaction was controlled with a Polyscience (71, Niles, USA) immersion recirculating water bath heater pump and the solution was mixed using a Fisatom apparatus (752a, São Paulo, Brazil) with magnetic stirring. The $\mathrm{pH}$ measurements were performed using a Hanna $\mathrm{pH}$ meter (HI 2221, Woonsocket, USA). The hydrated $\mathrm{SbCl}_{5}$ was centrifuged for $7 \mathrm{~min}$ at 4,600 $\times \mathrm{g}$ in an Eppendorf equipment (5430 R, Hauppauge, USA) for the precipitation of $\mathrm{Sb}$ pentoxide. A Büchi Labortechnik AG rotary evaporator (R-114, Flawil, Switzerland), equipped with a B-480 water bath, was used to concentrate MA formulations. An Eletrolab climate chamber (EL 101/1, São Paulo, Brazil) was used for accelerated drug stability tests. For mass measurements, an AUX220 Shimadzu balance (Tokyo, Japan) with a precision of $\pm 0.0001 \mathrm{~g}$ was used.

HG-AAS measurements were performed using a SpectrAA-240 atomic absorption spectrometer (Agilent Technologies, Santa Clara, USA), equipped with a VGA-77 continuous flow hydride generator accessory. Antimony cathode lamps (Agilent Technologies) were used at wavelengths of $217.6 \mathrm{~nm}$, with a $0.5 \mathrm{~nm}$ spectral bandpass and a current of $7 \mathrm{~mA}$. High purity argon was used as a purge gas at a flow rate of $90 \mathrm{~mL} \mathrm{~min}^{-1}$. A quartz tube cell was heated under the flame and used for $\mathrm{Sb}$ atomization.

\section{Reagents and solutions}

The following reagents were used in the syntheses of MA: $N$-methyl-D-glucamine (NMG), antimony(V) chloride $\left(\mathrm{SbCl}_{5}\right)$ and hydrochloric acid $(\mathrm{HCl})$, from Aldrich Chemical Co. (Milwaukee, USA), potassium hexahydroxoantimoniate $\left[\mathrm{KSb}(\mathrm{OH})_{6}\right]$, from Fluka Chemie $\mathrm{GmbH}$ (Buchs, Switzerland) and potassium hydroxide (KOH), from Química Moderna (Barueri, Brazil). Acetone from Merck KGaA (Darmstadt, Germany) was used in MA precipitation.

In the preparation of MA formulations for topical use, the gelling agent hydroxyethyl cellulose (HEC), or Natrosol $^{\odot}$, was obtained from Merck KGaA, (Darmstadt, Germany) and propylene glycol was obtained from Vetec Química Fina (Duque de Caxias, Brazil). 
High-purity reagents were used in all experiments and, in the preparation of aqueous solutions, ultrapure water was used, obtained with a Direct-Q 3 system (Millipore, Burlington, USA) with resistivity of $18.2 \mathrm{M} \Omega \mathrm{cm}$.

\section{Synthesis procedure for meglumine antimoniate}

The MA was synthesized from an equimolar mixture in water of NMG and $\mathrm{Sb}^{\mathrm{V}} \cdot{ }^{17}$ Two different synthetic routes were evaluated as a function of the $\mathrm{Sb}^{\mathrm{v}}$ source:

(i) $\mathrm{SbCl}_{5}$ : the hydration of $\mathrm{SbCl}_{5}$ was carried out with ultra-pure water in an exothermic reaction, yielding hydrochloric acid and antimony pentoxide. ${ }^{26}$ The mixture was centrifuged for $7 \mathrm{~min}$ at $4,600 \times \mathrm{g}$ to precipitate $\mathrm{Sb}_{2} \mathrm{O}_{5}$. The supernatant was discarded and the precipitate was transferred to a round-bottom flask immersed in the water bath under magnetic stirring. After the solution reached the bath temperature, NMG was added.

(ii) $\mathrm{KSb}(\mathrm{OH})_{6}: \mathrm{KSb}(\mathrm{OH})_{6}$ was dissolved in ultra-pure water in a round-bottom flask dipped in the water bath under magnetic stirring at $80^{\circ} \mathrm{C}$. After complete dissolution, the solution was cooled to the specific temperature of the synthesis and NMG was then added.

In both synthetic routes, after the addition of NMG, the solution turned whitish color. The reaction immediately began with a sudden decrease in $\mathrm{pH}$. If the beginning of the reaction was not observed and the $\mathrm{pH}$ of the solution became basic due to NMG solubilization, $1.0 \mathrm{~mol} \mathrm{~L}^{-1} \mathrm{HCl}$ would be added until $\mathrm{pH}$ reached a value close to 7 . Under this experimental condition, the reaction immediately began. The $\mathrm{pH}$ was increased with the addition of $1.0 \mathrm{~mol} \mathrm{~L}^{-1} \mathrm{KOH}$, keeping the value recommended for synthesis throughout the reaction. The $\mathrm{pH}$ was controlled until the solution cleared and the $\mathrm{pH}$ stabilized. After the end of the reaction, heating and stirring were switched off and the solution was allowed to cool down. Acetone was added in the amount of 3 times the volume of the resulting solution. After precipitation of MA, supernatant was discarded and the precipitate was dried at room temperature.

\section{Optimization strategy for the synthesis of meglumine antimoniate}

The optimization of the synthesis was aimed at the obtention of MA compounds with low levels of $\mathrm{Sb}^{\mathrm{III}}$. As several variables can influence the result, a screening experiment was performed according to fractional factorial design, ${ }^{23,24}$ to determine the experimental variables that significantly influence the result using a reduced number of experiments.
The significance of the effects was estimated by the Pareto chart that shows the absolute values of the standardized effects. Standardized effects are $t$-statistics that evaluate the null hypothesis that the effect is 0 through the $p$-value. This value represents the probability that the effect of a variable is caused exclusively by random error. Thus, considering the maximum $\alpha$ probability that would be subject to risk that the value of the effect is confused with its error, if $p \leq \alpha$ or $\left|t_{\text {calc }}\right| \geq t_{\alpha}$, the effect of the corresponding variable is significant.

After the screening experiments, RSM was performed to determine the optimal condition of MA synthesis, using two different sources of $\mathrm{Sb}^{\mathrm{v}}\left(\mathrm{SbCl}_{5}\right.$ and $\left.\mathrm{KSb}(\mathrm{OH})_{6}\right)$. The factor that presented no significant effect on the response was fixed, and the factors which affected the response were optimized simultaneously by application of $\mathrm{CCD} .{ }^{25}$ The exploration of each synthetic route included a total of $2^{\mathrm{k}}+2 \mathrm{k}+\mathrm{n}$ experiments, where $\mathrm{k}$ is the number of factors studied, $2^{\mathrm{k}}$ are the points of the factorial experiments carried out in the corners of the cube, $2 \mathrm{k}$ are the points carried out on the star centered on the face and $\mathrm{n}$ is the number of experiments performed at the central point of the experimental domain. The repetition of the central points was used to estimate the variance. The adequacy and significance of the quadratic model were assessed by analysis of variance (ANOVA), using Fisher $F$-test. The significant terms for each response were those that presented a $p$-value greater than $F$ at $95 \%$ confidence level.

All experiments were performed randomly. The software Statistica version 10 was used to model the experimental designs. ${ }^{27}$

\section{Meglumine antimoniate formulations for oral and topical treatment}

After the optimization of the experimental conditions of MA synthesis to achieve a low level of $\mathrm{Sb}^{\mathrm{III}}$ residue, formulations were designed for oral and topical treatment, by choosing simple and scalable processes. The MA compounds were synthesized according to the protocol described in the "Synthesis procedure for meglumine antimoniate" subsection, replacing the precipitation step by adjusting the concentration in a rotary evaporator equipment in the values of 300 and $850 \mathrm{mg} \mathrm{Sb} \mathrm{mL}^{-1}$ for oral and topical formulations, respectively. To prepare the topical formulations, a 1:1 v/v mixture of propylene glycol and water containing $2 \% \mathrm{~m} / \mathrm{v}$ hydroxyethyl cellulose was added to the MA solution $\left(850 \mathrm{mg} \mathrm{Sb} \mathrm{mL}^{-1}\right)$ at a proportion of $1: 1 \mathrm{v} / \mathrm{v}$ and the mixture was kept under agitation at $60^{\circ} \mathrm{C}$ for $30 \mathrm{~min}$.

To assess stability in terms of the formation of toxic sub-products (derived from $\mathrm{Sb}^{\mathrm{II}}$ ) and physicochemical 
properties, such as $\mathrm{pH}$, clarity of solutions and osmolarity (only for oral formulations), different formulations were prepared and monitored for a period of 45 and 90 days with a climatic chamber maintained at $40{ }^{\circ} \mathrm{C}$, after initial analysis. Multiple comparison tests using analysis of variance (ANOVA) were performed using the Statistica 10 software. ${ }^{27}$

\section{Results and Discussion}

\section{Optimization of meglumine antimoniate synthesis}

The optimization of MA synthesis was based on the study developed by Demicheli et al., ${ }^{17}$ using compounds from $0.004 \mathrm{~mol}$ of $\mathrm{Sb}^{\mathrm{v}}\left(\mathrm{SbCl}_{5}\right.$ or $\left.\mathrm{KSb}(\mathrm{OH})_{6}\right)$ and NMG.

\section{$2^{4-1}$ Fractional factorial planning}

In the optimization of MA synthesis conditions, four experimental variables and their interactions were investigated on the formation of $\mathrm{Sb}^{\mathrm{III}}$, namely: source of $\mathrm{Sb}^{\mathrm{v}}$ (1); temperature (2); water volume (3); and $\mathrm{pH}$ (4). In this sense, a $2^{4-1}$ fractional factorial design was performed and each assay was run in duplicate $\left(2^{4-1}=8\right.$ assays $\times$ duplicate $=$ 16 experiments). The experimental design matrix developed and the results obtained as $\% \mathrm{Sb}^{\mathrm{III}}$ related to the amount of total antimony present in the synthesized MA compounds in each experiment are shown in Table 1. The MA compounds obtained in these experiments showed average levels of $\mathrm{Sb}^{\text {III }}$, ranging from 0.1415 to $0.8955 \%$.

The Pareto chart (Figure 1) shows the standardized effects ( $t$-statistics) represented by bars and the limit of significance at $t_{0.05}$ with 8 degrees of freedom. According to the Pareto chart, only the $\mathrm{pH}$ variable (4) was not significant for the response at $95 \%$ confidence. The $\mathrm{Sb}^{\mathrm{III}}$ residue was higher when $\mathrm{SbCl}_{5}$, the lowest level (-), was used as an antimony source. The step that contributed to the high level of $\mathrm{Sb}^{\mathrm{II}}$ in MA compound prepared with $\mathrm{SbCl}_{5}$ was probably the hydration of this reagent, in which $\mathrm{SbCl}_{5}$ was added to a volume of ultra-pure water in an exothermically reaction. Additionally, the highest levels (+) of the volume and temperature variables contributed to the increased $\mathrm{Sb}^{\mathrm{III}}$ as a residue.

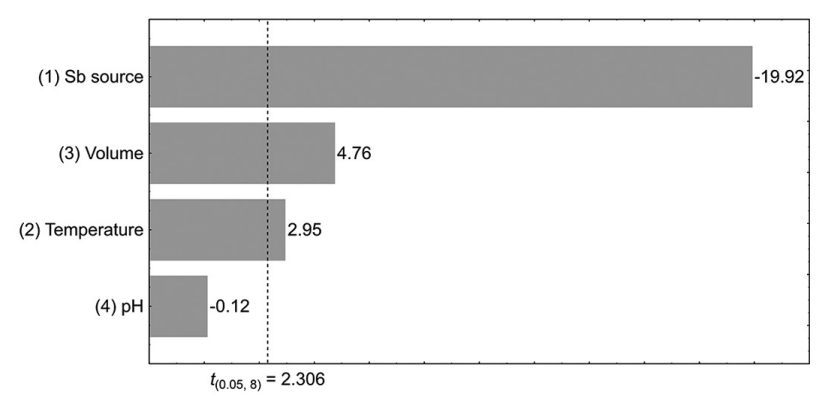

Figure 1. Pareto chart obtained in the $2^{4-1}$ fractional factorial design for the optimization of MA synthesis.

\section{CCD design for MA synthesis}

Although the screening experiment indicated the use of $\mathrm{KSb}(\mathrm{OH})_{6}$ was the most significant factor for obtaining MA compounds with lower levels of $\mathrm{Sb}^{\mathrm{II}}$, two considerations were relevant to keep the synthetic route using $\mathrm{SbCl}_{5}$. The first was related to the evidences that MA compounds obtained from $\mathrm{SbCl}_{5}$ showed better results in the leishmaniasis treatment tests for the VL murine model, orally. ${ }^{21}$ The latter was due to changing in the color of the aqueous solutions of the MA compounds obtained via $\mathrm{KSb}(\mathrm{OH})_{6}$ after a few weeks, indicating a possible degradation process. To decrease the contribution to the formation of $\mathrm{Sb}^{\mathrm{III}}$ during the $\mathrm{SbCl}_{5}$ hydration step, the procedure was changed to the dripping of ultra-pure water to a volume of $\mathrm{SbCl}_{5}$, generating a smaller amount of heat.

Response surface models were developed for each synthetic route, considering only the significant factors in $2^{4-1}$ fractional factorial design. The significant variables, volume (V) and temperature (T), were used for the construction of a CCD matrix with four experiments

Table 1. $2^{4-1}$ Fractional factorial design for MA synthesis and $\mathrm{Sb}^{\mathrm{III}}$ content obtained for the compounds in each assay. Values in parentheses are the coded values

\begin{tabular}{|c|c|c|c|c|c|c|}
\hline \multirow{2}{*}{$\frac{\text { Assay }}{1}$} & \multirow{2}{*}{$\frac{\mathrm{Sb}^{\mathrm{V}} \text { source }}{\mathrm{SbCl}_{5}(-1)}$} & \multirow{2}{*}{$\frac{\text { Temperature } /{ }^{\circ} \mathrm{C}}{55(-1)}$} & \multirow{2}{*}{$\frac{\text { Volume / mL }}{25(-1)}$} & \multirow{2}{*}{$\frac{\mathrm{pH}}{6(-1)}$} & \multicolumn{2}{|c|}{$\mathrm{Sb}^{\mathrm{III}}$ content $(\mathrm{n}=2) / \%$} \\
\hline & & & & & 0.499 & 0.540 \\
\hline 2 & $\mathrm{KSb}(\mathrm{OH})_{6}(+1)$ & $55(-1)$ & $25(-1)$ & $7(+1)$ & 0.128 & 0.155 \\
\hline 3 & $\mathrm{SbCl}_{5}(-1)$ & $70(+1)$ & $25(-1)$ & $7(+1)$ & 0.580 & 0.789 \\
\hline 4 & $\mathrm{KSb}(\mathrm{OH})_{6}(+1)$ & $70(+1)$ & $25(-1)$ & $6(-1)$ & 0.180 & 0.153 \\
\hline 5 & $\mathrm{SbCl}_{5}(-1)$ & $55(-1)$ & $40(+1)$ & $7(+1)$ & 0.762 & 0.746 \\
\hline 6 & $\mathrm{KSb}(\mathrm{OH})_{6}(+1)$ & $55(-1)$ & $40(+1)$ & $6(-1)$ & 0.193 & 0.199 \\
\hline 7 & $\mathrm{SbCl}_{5}(-1)$ & $70(+1)$ & $40(+1)$ & $6(-1)$ & 0.893 & 0.898 \\
\hline 8 & $\mathrm{KSb}(\mathrm{OH})_{6}(+1)$ & $70(+1)$ & $40(+1)$ & $7(+1)$ & 0.189 & 0.179 \\
\hline
\end{tabular}


in the factorial design $\left(2^{\mathrm{k}}\right)$, four experiments in the axial points (2k) and with three replicates in the central point (n), resulting in a total of eleven experiments. The $\mathrm{pH}$ parameter was not significant on the response, so it was maintained between 6 and 7 during all CCD experiments. The experimental design matrix and the results obtained as $\% \mathrm{Sb}^{\mathrm{II}}$ related to the presence of antimony in the synthesized MA compounds in each experiment of the synthetic routes via $\mathrm{KSb}(\mathrm{OH})_{6}$ and via $\mathrm{SbCl}_{5}$ are shown in Table 2.

Applying the CCD method, it was observed that the relationship between the response obtained and the variables followed the quadratic model expressed by the polynomial equations for the synthetic route via $\mathrm{SbCl}_{5}$ (equation 1).

$\mathrm{Sb}^{\mathrm{III}}(\%)=2.257-0.0748 \mathrm{~V}+1.48 \times 10^{-3} \mathrm{~V}^{2}-0.0596 \mathrm{~T}+$ $4.98 \times 10^{-4} \mathrm{~T}^{2}+5.86 \times 10^{-4} \mathrm{VT}$

Figure 2 shows the response surface of the model obtained for the $\% \mathrm{Sb}^{\mathrm{III}}$ property in MA compounds by synthetic routes via $\mathrm{SbCl}_{5}$. Analyzing that surface, it can be concluded that the $\mathrm{Sb}^{\text {III }}$ content in MA compounds reached a minimum value close to the central point, more specifically in the volume coordinate equal to $15.2 \mathrm{~mL}$ and in the temperature coordinate equal to $50.9^{\circ} \mathrm{C}$. It is worth mentioning that it is impracticable to keep the temperature unchanged throughout the synthesis, but it is important to use a bath with temperature control with a resolution of $\pm 0.1^{\circ} \mathrm{C}$. Likewise, a volume meter with an uncertainty of $0.1 \mathrm{~mL}$ should be used.

The ANOVA analysis showed that the regression was not significant for the model obtained in the synthetic route via $\mathrm{KSb}(\mathrm{OH})_{6}$, which can be explained by the low dispersion of the results for the analyzed levels. Thus, it was selected

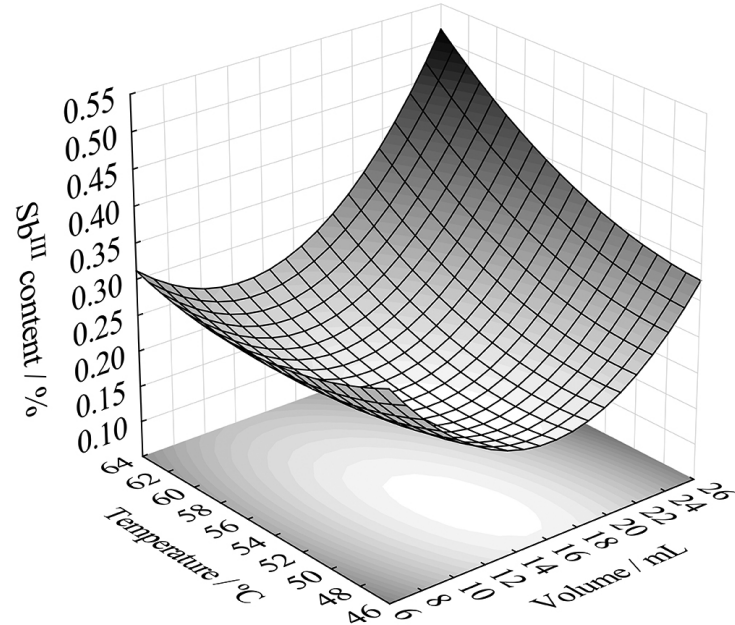

Figure 2. Response surface for the $\% \mathrm{Sb}^{\mathrm{III}}$ property out of total $\mathrm{Sb}$ in MA compounds obtained via $\mathrm{SbCl}_{5}$ synthetic route.

the central point as an optimal condition since lower $\mathrm{Sb}^{\mathrm{III}}$ content was obtained in this condition (Table 2). The quality of the models can be seen in Table 3 . The evaluation of the model obtained via $\mathrm{SbCl}_{5}$ synthetic route showed that the regression was significant while the lack-of-fit was nonsignificant. In addition, the explained variance values were above 0.90 , showed that the quadratic model is valid for this study. The signal-to-noise ratio was measured by the adequate precision, which comprises the value predicted at the points of the project and the average forecast error. In this study, the adequate precision values obtained were satisfactory, due to the signal-to-noise ratio higher than 4 .

Stability studies of oral and topical candidate formulations

During the optimization of MA synthesis, it was observed that aqueous solutions changed their color for

Table 2. CCD matrix of the MA synthesis optimization and $\mathrm{Sb}^{\mathrm{III}}$ content obtained for the MA compounds in each experiment. Values in parentheses are the coded values

\begin{tabular}{lcccc}
\hline Assay & Volume / $\mathrm{mL}$ & Temperature $/{ }^{\circ} \mathrm{C}$ & $\mathrm{Sb}^{\mathrm{III}} \mathrm{content}^{\mathrm{a}} / \%$ & $\mathrm{Sb}^{\mathrm{III}} \mathrm{content}^{\mathrm{b}} / \%$ \\
\hline 1 & $9.6(-1)$ & $50(-1)$ & 0.146 & 0.187 \\
2 & $22.4(+1)$ & $50(-1)$ & 0.196 & 0.237 \\
3 & $9.6(-1)$ & $60(+1)$ & 0.177 & 0.207 \\
4 & $22.4(+1)$ & $60(+1)$ & 0.296 & 0.332 \\
5 & $7.0(-\alpha)$ & $55(0)$ & 0.296 & 0.294 \\
6 & $25.0(+\alpha)$ & $55(0)$ & 0.135 & 0.346 \\
7 & $16.0(0)$ & $48(-\alpha)$ & 0.165 & 0.201 \\
8 & $16.0(0)$ & $62(+\alpha)$ & 0.174 & 0.248 \\
$\mathrm{CP}$ & $16.0(0)$ & $55(0)$ & 0.086 & 0.196 \\
$\mathrm{CP}$ & $16.0(0)$ & $55(0)$ & 0.127 & 0.172 \\
$\mathrm{CP}$ & $16.0(0)$ & $55(0)$ & 0.124 & 0.182 \\
\hline $\mathrm{KSb}(\mathrm{OH})_{6} \mathrm{Sy}$ & & & \\
\hline
\end{tabular}

${ }^{\mathrm{a}} \mathrm{KSb}(\mathrm{OH})_{6}$ synthetic route; ${ }^{\mathrm{b}} \mathrm{SbCl}_{5}$ synthetic route. $\alpha=1.414$; $\mathrm{CP}$ : central point. 
Table 3. Statistical parameters obtained from analysis of variance (ANOVA) for the optimization study using CCD analysis $(p=0.05)$

\begin{tabular}{lccccc}
\hline Synthetic route & Regression $(p$-value $)$ & Lack-of-fit $(p$-value $)$ & $\mathrm{R}^{2}$ & $\mathrm{R}_{\max }^{2}$ & Adeq. precision \\
\hline $\mathrm{KSb}(\mathrm{OH})_{6}$ & 0.504 & 0.068 & 0.50 & 0.98 & 5.91 \\
$\mathrm{SbCl}_{5}$ & 0.017 & 0.108 & 0.90 & 0.99 & 20.09 \\
\hline
\end{tabular}

$\mathrm{R}^{2}$ : explained variation; $\mathrm{R}_{\max }^{2}$ : maximum explained variation; Adeq. precision: signal-to-noise ratio.

MA compounds prepared via $\mathrm{KSb}(\mathrm{OH})_{6}$ route in a few weeks. Thus, it was decided to carry out the stability study only with the MA compounds obtained via $\mathrm{SbCl}_{5}$ prepared according to optimized conditions in formulations for oral (OF1-OF4) and topical (TF1-TF4) administration. Four replicates of each formulation were prepared, which were divided into 3 aliquots to be analyzed at different times from the date of manufacture (0, 45 and 90 days). The aliquots monitored for 45 and 90 days were kept in a climate chamber at $40^{\circ} \mathrm{C}$. The formulations and evaluation of $\mathrm{pH}$, $\mathrm{Sb}^{\mathrm{III}}$ content and osmolarity values are shown in Figures 3 and 4 . The mean value for $\mathrm{Sb}^{\mathrm{III}}$ content was $0.174 \pm 0.056 \%$, which is very close to the theoretical $(0.172 \%)$, obtained by solving equation 1 in the optimal condition. The value of $\mathrm{Sb}^{\mathrm{III}}$ content obtained in the optimized condition of the MA synthesis demonstrates the effect of multivariate

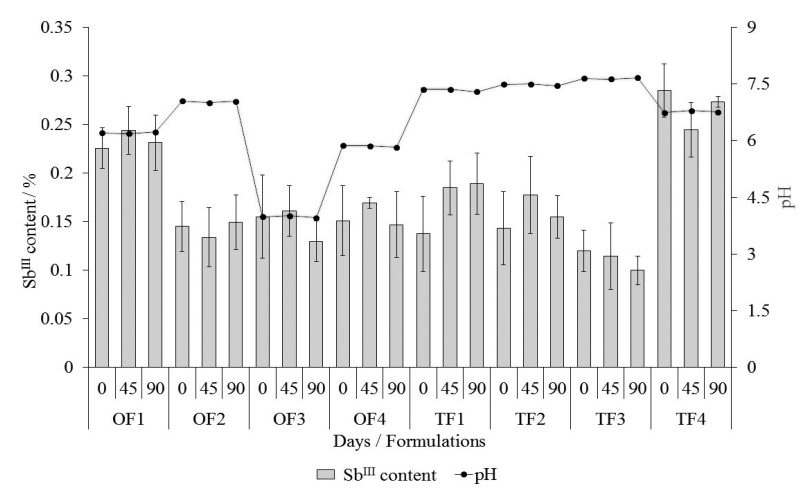

Figure 3. Results of the $\mathrm{Sb}^{\mathrm{III}}$ content and $\mathrm{pH}$ values for oral (OF1-OF4) and topical (TF1-TF4) MA formulations during 90 days of stability studies. The vertical bars represent the standard deviation.

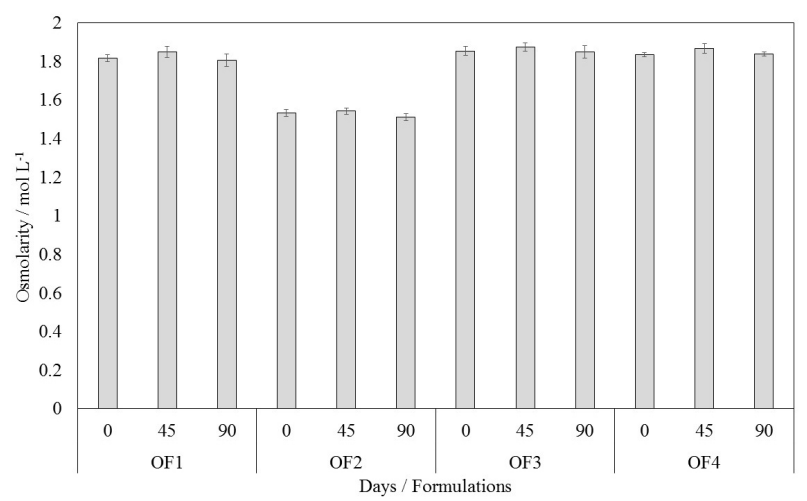

Figure 4. Results of the osmolarity values for oral (OF1-OF4) MA formulations during 90 days of stability studies. The vertical bars represent the standard deviation. optimization in reducing $\mathrm{Sb}^{\mathrm{III}}$ levels. In another study, Cabral et al..$^{28}$ described the development of an injectable MA formulation and obtained percentages of $\mathrm{Sb}^{\mathrm{III}}$ out of total $\mathrm{Sb}$ ranging from 1.16 to $4.57 \%$. Regarding commercial drug, the reported percentages of $\mathrm{Sb}^{\mathrm{II}}$, out of total $\mathrm{Sb}$, vary in large orders of magnitude, ranging from values between $0.09-0.30 \% \%^{22,29-31}$ to values higher than $30 \% .32$

Multiple comparison tests using analysis of variance (ANOVA) were performed for each MA formulation and for each parameter ( $\mathrm{Sb}^{\mathrm{III}}$ content, $\mathrm{pH}$ and osmolarity), considering the data analyzed at 0,45 and 90 days. Data homogeneity and normality were confirmed through the Levene ( $p$-values ranging from 0.176 to 0.963 ) and Shapiro-Wilk ( $p$-values ranging from 0.119 to 0.993 ) tests, respectively. The $p$-values (ranging from 0.054 to 0.796 ) for multiple comparisons, using ANOVA, showed that there were no significant variations of each parameter for the formulations during the 90 days, confirming the stability of the MA formulations.

\section{Conclusions}

This study demonstrated the applicability of multivariate optimization for the synthesis of meglumine antimoniate to obtain a formulation with low $\mathrm{Sb}^{\mathrm{II}}$ contents for a more efficient and safe leishmaniasis treatment.

Candidate formulations for oral and topical administration prepared with $\mathrm{SbCl}_{5}$ were obtained under optimized conditions and presented $\mathrm{Sb}^{\mathrm{III}}$ contents close to the theoretical value. Multiple comparison tests using ANOVA for each studied parameter ( $\mathrm{Sb}^{\mathrm{III}}$ content, $\mathrm{pH}$ and osmolarity) showed that no significant changes in the formulations during 90 days were observed, confirming the stability of the monitored MA formulations at $40^{\circ} \mathrm{C}$. On the other hand, MA formulations prepared with $\mathrm{KSb}(\mathrm{OH})_{6}$ showed changing in the color after a few days of preparation, which means possible indication of instability and degradation process.

\section{Acknowledgments}

We are grateful for the financial support and scholarships from the Brazilian agencies Conselho Nacional de Desenvolvimento Cientifico e Tecnologico (CNPq) and 
Coordenação de Aperfeiçoamento de Pessoal de Nível Superior (CAPES).

\section{References}

1. https://www.who.int/en/news-room/fact-sheets/detail/ leishmaniasis, accessed in April 2021.

2. Rath, S.; Trivelin, L. A.; Imbrunito, T. R.; Tomazela, D. M.; de Jesús, M. N.; Marzal, P. C.; Quim. Nova 2003, 26, 550.

3. Sneader, W.; Drug Discovery: A History, $1^{\text {st }}$ ed.; John Wiley \& Sons Ltd: Chichester, UK, 2005.

4. Frézard, F.; Demicheli, C.; Ribeiro, R. R.; Molecules 2009, 14, 2317.

5. Haldar, A. K.; Sen P.; Roy, S.; Mol. Biol. Int. 2011, 2011, 571242 .

6. Lawn, S. D.; Armstrong, M.; Whitty, C. J.; Trans. R. Soc. Trop. Med. Hyg. 2006, 100, 264.

7. Goyard, S.; Segawa, H.; Gordon, J.; Showalter, M.; Duncan, R.; Turco, S. J.; Beverley, S. M.; Mol. Biochem. Parasitol. 2003, $130,31$.

8. Burguera, J. L.; Burguera, M.; Petit de Peña, Y.; Lugo, A.; Anez, N.; Trace Elem. Med. 1993, 10, 66.

9. Lugo de Yarbuh, A.; Anez, N.; Petit de Peña, Y.; Burguera, J. L.; Burguera, M.; Ann. Trop. Med. Parasitol. 1994, 88, 37.

10. Marquis, N.; Gourbal, B.; Rosen, B. P.; Mukhopadhyay, R.; Ouellette, M.; Mol. Microbiol. 2005, 57, 1690.

11. Ponte-Sucre, A.; Gamarro, F.; Dujardin, J. C.; Barrett, M. P.; López-Vélez, R.; García-Hernández, R.; Pountain, A. W.; Mwenechanya, R.; Papadopoulou, B.; PLoS Neglected Trop. Dis. 2017, 11, e0006052.

12. Kato, K. C.; Morais-Teixeira, E.; Reis, P. G.; Silva-Barcellos, N. M.; Salaüm, P.; Campos, P. P.; Corrêa-Junior, J. D.; Rabello, A.; Demicheli, C.; Frézard, F.; Antimicrob. Agents Chemother. 2014, 58, 481.

13. Wyllie, S.; Cunningham, M. L.; Fairlamb, A. H.; J. Biol. Chem. 2004, 279, 39925.

14. Wyllie, S.; Fairlamb, A. H.; Biochem. Pharmacol. 2006, 71, 257.

15. Timerstein, M. A.; Plews, P. I.; Walker, C. V.; Woolery, M. D.; Wey, H. E.; Toraason, M. A.; Toxicol. Appl. Pharmacol. 1995, $130,41$.

16. Pulido, M. D.; Parrish, A. R.; Mutat. Res. 2003, 533, 227.

17. Demicheli, C.; Ochoa, R.; Lula, I. S.; Gozzo, F. C.; Eberlin, M. N.; Frézard, F.; Appl. Organomet. Chem. 2003, 17, 226.
18. Carvalho, S. H.; Frézard, F.; Pereira, N. P.; Moura, A. S.; Ramos, L. M. Q. C.; Carvalho, G. B.; Rocha, M. O. C.; Trop. Med. Int. Health 2019, 24, 380.

19. Téllez, J.; Echeverry, M. C.; Romero, I.; Guatibonza, A.; Santos Ramos, G.; de Oliveira, A. C. B.; Frézard, F.; Demicheli, C.; J. Liposome Res. 2021, 31, 169.

20. Dzamitika, S. A.; Falcão, C. A. B.; Oliveira, F. B.; Marbeuf, C.; Garnier-Suillerot, A.; Demicheli, C.; Rossi-Bergmann, B.; Frézard, F.; Chem. Biol. Interact. 2006, 160, 217.

21. Kato, K. C.; Morais-Teixeira, E.; Islam, A.; Leite, M. F.; Demicheli, C. P.; de Castro, W. V.; Corrêa-Junior, J. D.; Rabello, A.; Frézard, F.; Antimicrob. Agents Chemother. 2018, 62, e00539-18.

22. Fabrino, H. J. F.; Demicheli, C. P.; Frezard, F. J. G.; Costa, L. M.; J. Braz. Chem. Soc. 2021, 32, 11.

23. Neto, B. B.; Scarminio, I. S.; Bruns, R. E.; Como fazer Experimentos: Pesquisa e Desenvolvimento na Ciência e na Indústria, $2^{\text {nd }}$ ed.; Ed. Unicamp: Campinas, Brazil, 2002.

24. Lundstedt, T.; Seifert, E.; Abramo, L.; Theilin, B.; Nyström, A.; Pettersen, J.; Bergman, R.; Chemom. Intell. Lab. Syst. 1998, 42, 3.

25. Myers, R. H.; Montgomery, D. C.; Response Surface Methodology: Process and Product Optimization Using Designed Experiments, $3^{\text {rd }}$ ed.; John Wiley \& Sons: New York, USA, 2009.

26. Budavari, S.; The Merck Index: An Encyclopedia of Chemicals, Drugs and Biologicals, $11^{\text {th }}$ ed.; Merck and Co. Inc.: Rahway, USA, 1989.

27. Statistica, version 10; StatSoft, Inc., USA, 2010.

28. Cabral, L. M.; Juliano, V. N. M.; Dias, L. R. S.; Dornelas, C. B.; Rodigues, C. R.; Villardi, M.; Castro, H. C.; Santos, T. C.; Mem. Inst. Oswaldo Cruz 2008, 103, 130.

29. Santos, V. S.; Santos, W. D. R.; Kubota, L. T.; Tarley, C. R. T.; J. Pharm. Biomed. Anal. 2009, 50, 151.

30. Lukaszczyk, L.; Zyrnicki, W.; J. Pharm. Biomed. Anal. 2010 , $52,747$.

31. Seby, F.; Gleyse, C.; Grosso, O.; Plau, B.; Donard, O. F. X.; Anal. Bioanal. Chem. 2012, 404, 2939.

32. Salaün, P.; Frézard, F.; Anal. Bioanal. Chem. 2013, 405, 5201.

Submitted: October 20, 2020

Published online: April 19, 2021 